\title{
Assessment of Design Alternation via 2D Physical Modelling in the Main Breakwater of Colombo Port Expansion Project
}

\author{
A. Silva ${ }^{1}$, K. Subasinghe ${ }^{2}$, C.Rajapaksha ${ }^{3}$, K.Raveenthiran ${ }^{4}$, S.H Kim ${ }^{5}$, M.Young6 \\ H.N.R.Perera ${ }^{7}$, Susumu Araki 8 \\ ${ }^{1}$ Dept. of Civil Engineering, Osaka University, silva_a@civil.eng.osaka-u.ac.jp \\ ${ }^{2}$ Engineering Manager, Lanka Hydraulic Institute., kaushalya.subasinghe@lhi.lk \\ ${ }^{3}$ Research Engineer, Lanka Hydraulic Institute., chathuri.rajapaksha@lhi.lk \\ ${ }^{4}$ Senior Engineering Manager, Lanka Hydraulic Institute., ravi@1hi.lk \\ 5 Project Manager, Hyundai Engineering \& Construction., kimsh@hdec.co.kr \\ 6 Project Manager, Scott Wilson Group plc., martin.young@ scottwilson.lk \\ ${ }^{7}$ CEO, Lanka Hydraulic Institute., nissanka.perera@lhi.lk \\ ${ }^{8}$ Associate Professor, Osaka University., araki@ civil.eng.osaka-u.ac.jp
}

\begin{abstract}
Colombo Port Expansion Project was initiated with the recognition of increment in demand for container throughput in future. Construction works of the project are in progress. The toe of the main breakwater contains $8-12 \mathrm{~T}$ large boulders. Whilst the construction of main breakwater is in progress, contractor faced difficulties to find the $8-12 \mathrm{~T}$ rock boulders from queries for toe. Hence, application of 20 $\mathrm{T}$ CORE-LOC instead of 8-12T was proposed by the contractor. Two dimensional (2D) physical model testing was carried out to assess the stability of toe in main breakwater with two or three CORE-LOC (20T) rows instead of $8-12 \mathrm{~T}$ boulders. Model scale was determined considering flume dimensions, sea bed profile, available CORE-LOC miniatures and wave heights to be tested and dimensions of the breakwater section etc. Scaling down of the prototype to model was done according to the Froude's Similarity and model units (armour units, CORE-LOC) were scaled down based on Hudson's Stability Criterion. Several alternative design sections were subjected to the testing and higher emphasis was set to maintain the specified rock gradations. Study determined the adequate number of CORE-LOC rows to replace the existing 8-12T large boulders layers while considering overall stability of the breakwater.
\end{abstract}

Key Words : CORE-LOC, Froude's Similarity, Hudson's Stability Criterion, Model Scale

\section{INTRODUCTION}

With the recognition of increment in demand for container throughput in future; the Government of Sri Lanka recognized the need to increase the Colombo Port's capacity to maintain its status as a hub in South Asia. The Port of Colombo, one of the few deepwater ports in the Indian subcontinent, is strategically placed along the main shipping route connecting East and Southeast Asia with Europe, and
North and South America. Initial feasibility studies were carried out with assistance from Asian Development Bank. The harbour is located west to the existing southwest breakwater having area of approximately 600 hectares with harbour basin area of 290 hectares (Fig. 1). It has four terminals of over $1200 \mathrm{~m}$ in length each to accommodate 3 berths with entrance channel of $20 \mathrm{~m}$ depth, $600 \mathrm{~m}$ turning circle and harbour basin depth of $18 \mathrm{~m}$. The port expansion w scheduled to carry out in two phases. 
Under Phase 1, Breakwater and three terminals are to be constructed and, currently first phase is in progress. With the completion of Phase 1, breakwater extension with the fourth terminal will be done.

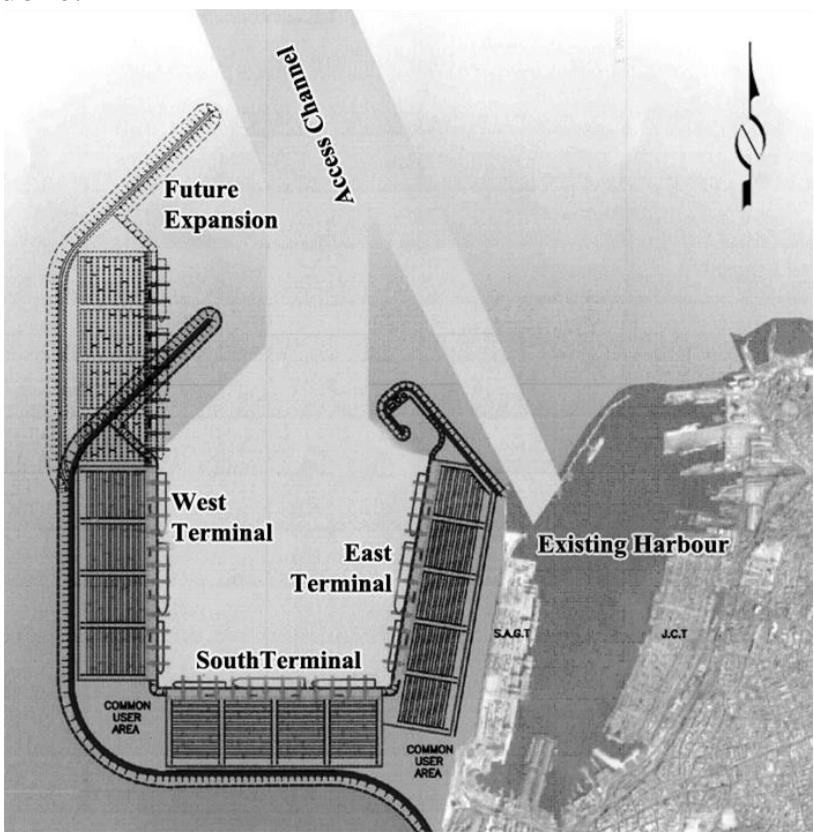

Fig. 1 Colombo Port Expansion Project

Whilst the construction of main breakwater is in progress, the contractor faced difficulties to find the 8 $-12 \mathrm{~T}$ rock boulders (Fig. 2) from the queries for toe construction. Hence it was proposed to change the breakwater toe design by changing the large boulders $(8-12 \mathrm{~T})$ in to the CORE-LOC (20T) by contractor. Consequently, 2D (Flume) Physical model testing was carried out to check the toe stability in the physical modelling facility at Lanka Hydraulic Institute ltd, Katubedda, Sri Lanka. The facility consisted with $30 \mathrm{~m}$ long, $0.8 \mathrm{~m}$ wide and $1 \mathrm{~m}$ deep flume ${ }^{1)}$.

\section{OBJECTIVES}

The main objective of the $2 \mathrm{D}$ physical model studies on the alternative breakwater sections was to assess the stability of toe of the main breakwater with two or three CORE-LOC (20T) rows.

\section{MODEL DETAILS}

\section{(1) Model Scale}

Model scale of 1:48 was selected based on the following factors; ensuring that the interaction of wave/structure is represented precisely without the results being biased by the scale effect.

1. Flume dimensions $(30 \mathrm{~m} \times 0.8 \mathrm{~m} \times 1.6 \mathrm{~m}$ in length, width and depth respectively)

2. Length and depth of the sea bed profile

3. Overall width of the breakwater section

4. Final crest level of the breakwater section

5. Wave heights to be tested

6. Available CORE-LOC miniatures

\section{(2) Model Units}

All the model units were scaled down based on the following Hudson's Stability Criterion (1979). Only one type of CORE-LOC armour units were used for the breakwater section. The actual CORE-LOC units in the site are $8.5 \mathrm{~m}^{3}$ in volume and $2396 \mathrm{~kg} / \mathrm{m}^{3}$ in density

$$
\frac{\left(W_{n 50}\right)_{m}}{\left(W_{n 50}\right)_{p}}=\frac{\left(H_{s}\right)_{m}{ }^{3} \rho_{s m}\left[\frac{\rho_{s}}{\rho_{w}}-1\right]_{p}^{3}}{\left(H_{s}\right)_{p}{ }^{3} \rho_{s p}\left[\frac{\rho_{s}}{\rho_{w}}-1\right]_{m}^{3}}
$$

Where;

$\left(\mathrm{W}_{\mathrm{n} 50}\right)_{\mathrm{m}} \quad=$ Weight of armour in the model

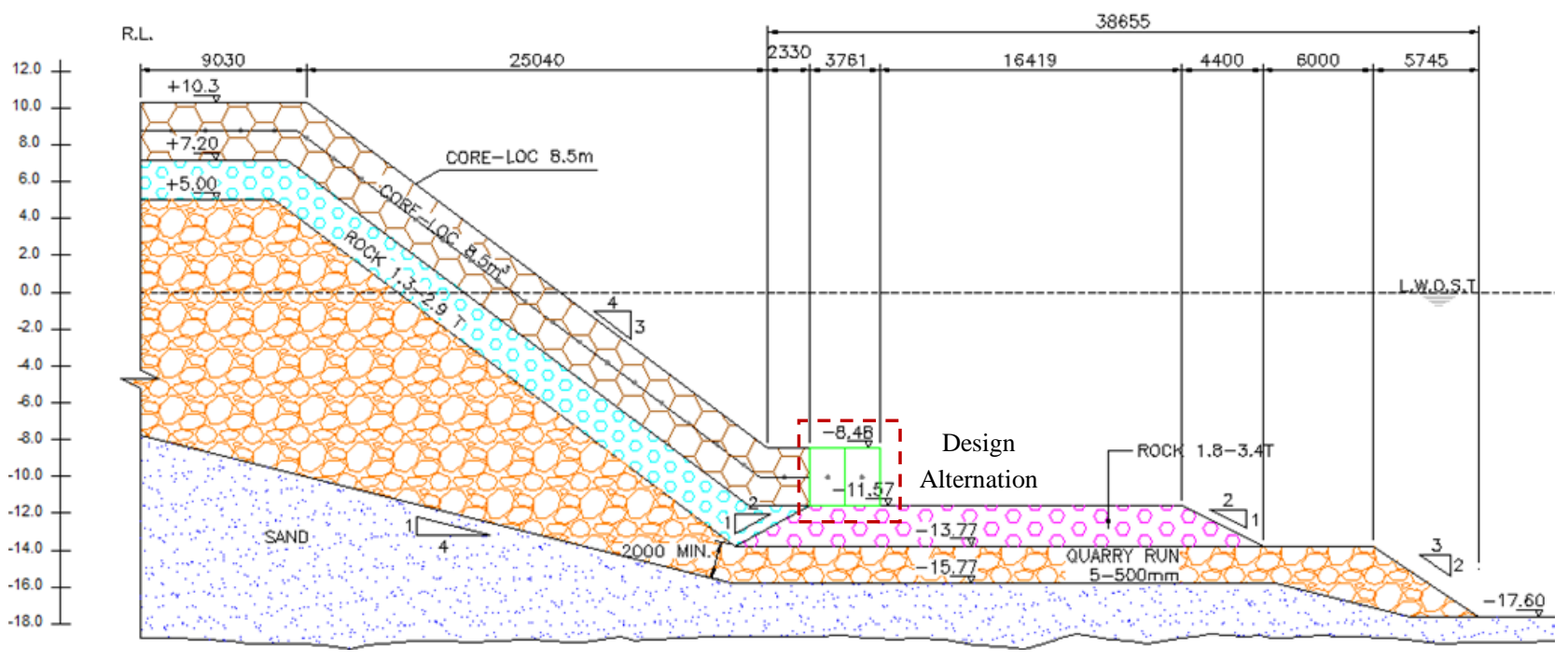

Fig. 2 Alternative Section at Chainage 3100 with CORE-LOC in Toe (T1 - T2) 
$\left(\mathrm{W}_{\mathrm{n} 50}\right)_{\mathrm{p}}=$ Weight of armour in the prototype

$\left(\mathrm{H}_{\mathrm{S}}\right)_{\mathrm{m}} \quad=$ Significant wave height in the model

$\left(\mathrm{H}_{\mathrm{S}}\right)_{\mathrm{p}} \quad=$ Significant wave height in the prototype

$\rho_{\mathrm{sm}} \quad=$ Density of armour in the model

$\left(\rho_{\mathrm{s}}\right)_{\mathrm{p}} \quad=$ Density of armour in the prototype

$\rho_{\mathrm{wm}} \quad=$ Density of fresh water in the model

$\rho_{\mathrm{wp}} \quad=$ Density of sea water in the prototype

Regarding the density of model CORE-LOC Units, varying type of densities were used. Model CORE-LOC units absorb considerable amount of water and comparison of weight during storage and saturated condition are shown in Table 1. The average volume of a model CORE-LOC is $56 \mathrm{~cm}^{3}$.

Based on the available model CORE-LOC units, $80 \%$ of the model units represent prototype CORELOC, having volume of $8.1 \mathrm{~m}^{3}$ or less than that. Balance of $20 \%$ represents prototype CORE-LOC units having volume more than $8.1 \mathrm{~m}^{3}$. These volumes are represented based on the scale 1:48. Hence the selection of 1:48 scale is a conservative approach.

Table 1 Distribution of normal and saturated weights of CORE-LOC miniatures

\begin{tabular}{|c|c|c|}
\hline Percentage $\%$ & $\begin{array}{c}\text { Weight During } \\
\text { Storage }(\mathrm{g})\end{array}$ & $\begin{array}{c}\text { Saturated Weight } \\
(\mathrm{g})\end{array}$ \\
\hline 0 & 124.37 & 133.47 \\
\hline 10 & 126.19 & 134.82 \\
\hline 20 & 126.73 & 135.52 \\
\hline 30 & 126.97 & 135.81 \\
\hline 40 & 127.42 & 136.12 \\
\hline 50 & 127.73 & 136.6 \\
\hline 60 & 128.21 & 137.25 \\
\hline 70 & 128.65 & 137.56 \\
\hline 80 & 128.96 & 137.89 \\
\hline 90 & 130.06 & 138.52 \\
\hline 100 & 131.21 & 141.4 \\
\hline
\end{tabular}

Two types of rock units were used in the testing of model sections. Under layer rock armour units are 1.3-2.9T and 1.8-3.4T in prototype and density of $2700 \mathrm{~kg} / \mathrm{m}^{3}$ has been assumed. Since fresh water is being used in the flume instead of sea water, the density difference was taken in to account in the model unit weight calculations.

Gradation of Rock units for the model test was done according to the CIRIA (CIRIA. CUR., CETMEF. "The Rock Manual: The use of rock in hydraulic engineering", $2^{\text {nd }}$ ed., C683, CIRIA,
London, 2007) ${ }^{2)}$ specifications (Table 2) and based on the site specifications.

Quarry run with varying size of $5-500 \mathrm{~mm}$ was to be used. Decision of percentage allocation for different diameters was done according to the CIRIA manual and specifications given by the site. According to the specifications, ratio $\mathrm{D}_{85} / \mathrm{D}_{15}$ should be within the range of 2.5-5.0. During the model tests it was maintained as 3.2.

For the model test, sand having $\mathrm{D}_{50}=0.14 \mathrm{~mm}$ was used.

Table 2 Distribution of normal and saturated weights of Gradation limits for $1.3-2.9 \mathrm{~T}$ and $1.8-3.4 \mathrm{~T}$ Rock Classes

\begin{tabular}{|c|c|c|c|c|c|c|}
\hline \multirow{3}{*}{$\begin{array}{l}\text { Grading } \\
\text { Class } \\
\text { Designat } \\
\text { ion }\end{array}$} & \multirow{2}{*}{\multicolumn{4}{|c|}{$\begin{array}{c}\text { Heavy Grading Class } \\
\text { requirements }\end{array}$}} & \multirow{3}{*}{\multicolumn{2}{|c|}{$\begin{array}{c}\text { Effective } \\
\text { Mean Weight }\end{array}$}} \\
\hline & & & & & & \\
\hline & $\begin{array}{c}\text { Extre } \\
\text { me }\end{array}$ & Lower & Upper & $\begin{array}{c}\text { Extre } \\
\text { me }\end{array}$ & & \\
\hline \multirow[b]{2}{*}{ (Tonnes) } & $\begin{array}{l}\text { (ELC } \\
\mathrm{L})\end{array}$ & (LCL) & $\begin{array}{c}\text { (UCL } \\
\text { ) }\end{array}$ & $\begin{array}{l}\text { EUC } \\
\text { L) }\end{array}$ & & \\
\hline & $\begin{array}{l}\mathrm{y}< \\
2 \%\end{array}$ & $\begin{array}{c}0 \%< \\
y< \\
10 \%\end{array}$ & $\begin{array}{l}70 \% \\
<y<1 \\
00 \%\end{array}$ & $97 \%$ & $\min$ & $\max$ \\
\hline $0.3-1.0$ & 0.2 & 0.3 & 1 & 1.5 & 0.54 & 0.69 \\
\hline $1-3$ & 0.65 & 1 & 3 & 4.5 & 1.7 & 2.1 \\
\hline $3-6$ & 2 & 3 & 6 & 9 & 4.2 & 4.8 \\
\hline $6-10$ & 4 & 6 & 10 & 15 & 7.5 & 8.5 \\
\hline $1.8-3.4$ & 1.2 & 1.8 & 3.4 & 5.1 & & \\
\hline $1.3-2.9$ & 0.9 & 1.3 & 2.9 & 4.4 & & \\
\hline
\end{tabular}

\section{(3) Coastal Profile}

Selection of coastal profile in front of the structure is limited by the flume dimensions and the model scale. The bed profile is comparatively flat with in the modelled area. Fig. 3 shows the bathymetry in the vicinity of main breakwater area and positions of the selected breakwater sections.

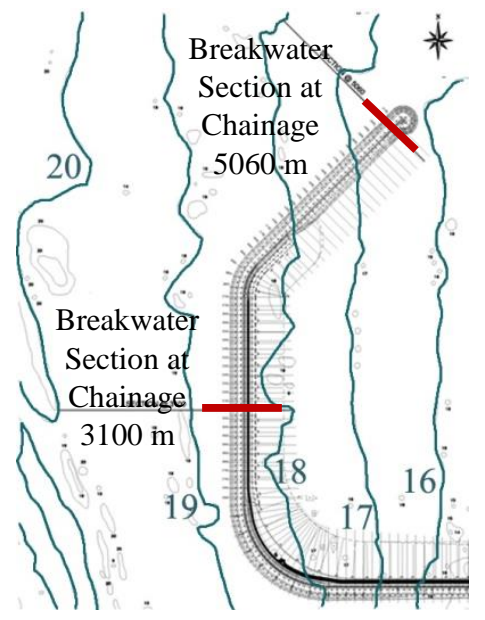

Fig. 3 Tested Breakwater Sections 


\section{(4) Model Construction}

Model constructions were mainly done to represent a deep water section and a shallow water section.

The selected sea bed profile was constructed on the flume bed with sand compacted to the required levels and covering it with a thin layer of cement mortar (non moveable bed). Relevant breakwater sections were constructed accordingly. The sequence of construction of model bed layer was;

1. Bed preparation

2. Core layer

3. Filter layers

4. Toe and armour layer placing

As the study concerned the toe stability; overtopping, stability of rear side and wave transmission were not assessed, therefore the crest wall and rear side of the breakwater section was not constructed. The method of placing of CORE-LOC armour and other units was done according to the specified placement patterns in order to ensure that correct packing density and stability will be achieved. Rocks and armours on all sections of the sea ward slope were painted with colours to improve the damage assessment.

CORE-LOCs in the toe layer were placed according to random cannon fashion and the others were placed randomly. During the placement of CORE-LOC vertical (Dv) and horizontal (DH) distances between centers were maintained as below.

$$
\begin{aligned}
& \mathrm{DH}=1.11 \mathrm{C} \\
& \mathrm{Dv}=0.55 \mathrm{C}
\end{aligned}
$$

Where, $\mathrm{C}=3.36$ (for $8.5 \mathrm{~m}^{3}$ CORE-LOC)

$\mathrm{C}$ is defined as the equivalent cube size of the armour unit

\section{(5) Model Calibration}

Prior to the construction of model sections, calibration runs were carried out for selected wave conditions to obtain the required wave conditions in front of the wave paddle. Calibration was done for both $0.0 \mathrm{~m}$ and $1.2 \mathrm{~m}$ (Chart Datum, CD) water levels for deep water section and shallow water section. Calibration curves were developed for waves of different wave periods and water levels. These calibration curves were applied to the input wave conditions to ensure the required wave conditions are achieved at the paddle.

To achieve the calibration, a wave absorption system consisting of perforated rubber sheet and a rubble mound slope at the end of the flume were placed. An array of 3 wave gauges was placed in front of the paddle to measure the wave conditions and analyze the separation of incident and reflected waves.

\section{(6) Model Testing}

Waves in the model were generated by a hydraulically operated paddle controlled by a PC based Wave Synthesiser software package developed by DHI Water and Environment, Denmark. The interface between the PC based software and DHI Active Wave Absorption Control system (AWACS) is established through the wave generator/ receiver unit. $\mathrm{AWACS}^{3)}$ is a digital control system that enables wave makers to simultaneously generate the desired waves and to absorb reflected waves online.

In the wave generation process, wave parameters $\left(\mathrm{H}_{\mathrm{s}}\right.$ and $\left.\mathrm{T}_{\mathrm{p}}\right)$ are specified. Thereafter, JONSWAP spectrum was used to create the input surface elevation time series through inverse Fast Fourier Transformation (FFT). The input signals, as well as output signals from the wave gauges originate as voltage time series. The sensitivity of wave gauges can be changed by changing the voltage - water level displacement relationship.

Due to the limited length of the flume, it is not possible to fully absorb all incoming wave energy at the back of the flume. Therefore wave heights are measured along the flume by providing special arrangement of wave gauges closer to the wave paddle and structure. This helped to measure incident wave heights as well as the reflected wave heights.

These wave gauges have two thin stainless steel electrodes that measure the wave height using the conductivity of water at respective locations. The accuracy of these wave gauges is $\pm 0.2 \mathrm{~mm}$ in the model. All the wave gauges were subjected to calibration prior to a model test.

\section{a) Test Conditions and Model Modifications}

Mainly, tests were carried out for a deep water section $(-18.5 m \mathrm{CD})$ in the trunk area of the main breakwater and shallow water section $\quad(-16.5 \mathrm{~m}$ CD) near to the head of the breakwater.

Model testing was conducted for the extreme wave conditions of $100 \mathrm{yr}$ and $200 \mathrm{yr}+20 \%$ return periods. Each test run represented the duration of at least $6 \mathrm{hr}$ storm in the prototype. Prior to commencing the actual test runs, some trial test runs for $10 \mathrm{yr}$ return periods for both water levels were carried out. This was to ensure that all the measuring equipments and data acquisition systems were in order.

Values for the significant wave heights are derived at the depth of $15 \mathrm{~m}$. Since the wave generation depth at the flume was different from that, wave heights at $15 \mathrm{~m}$ depths were transferred to respective depths. For the deep water section, waves at $24.5 \mathrm{~m}(0.0 \mathrm{~m} \mathrm{WL} \mathrm{CD})$ and $25.7 \mathrm{~m}(1.2 \mathrm{~m} \mathrm{WL} \mathrm{CD})$ were obtained through the linear wave transformation. Wave generation depths were set to 
$24.9 \mathrm{~m}$ and $26.1 \mathrm{~m}$ in the shallow water section. Tested wave heights are given in Table 3.

Table 3 Test Conditions

\begin{tabular}{|c|c|c|c|c|c|}
\hline 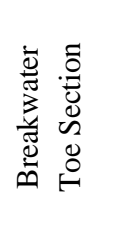 & 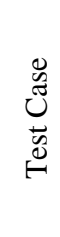 & 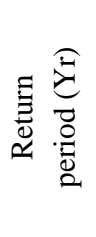 & 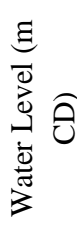 & $\begin{array}{ll}0 & 0 \\
2 & 0 \\
3 & 0 \\
3 & 0 \\
\frac{1}{3} & 0 \\
0 & 0 \\
2 & 0\end{array}$ & 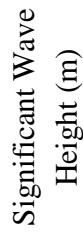 \\
\hline \multirow{6}{*}{$\begin{array}{c}2 \text { No } \\
\text { CORE-L } \\
\text { OC } \\
(-18.5 \mathrm{~m} \\
\text { CD) }\end{array}$} & $\mathrm{T} 1$ & 100 & 1.2 & 16 & 5.8 \\
\hline & $\mathrm{T} 2$ & $\begin{array}{c}200+ \\
20 \%\end{array}$ & 1.2 & 14 & 7.7 \\
\hline & T3 & 100 & 0.0 & 16 & 5.8 \\
\hline & $\mathrm{T} 4$ & $\begin{array}{c}200+ \\
20 \%\end{array}$ & 0.0 & 14 & 7.7 \\
\hline & T5 & $\begin{array}{c}200+ \\
20 \%\end{array}$ & 0.0 & 16 & 5.8 \\
\hline & T6 & $\begin{array}{c}200+ \\
20 \%\end{array}$ & 0.0 & 14 & 7.7 \\
\hline $\begin{array}{c}4 \text { No } \\
\text { CORE-L } \\
\text { OC } \\
(-18.5 \mathrm{~m} \\
\text { CD) }\end{array}$ & $\mathrm{T} 7$ & $\begin{array}{c}200+ \\
20 \%\end{array}$ & 0.0 & 14 & 7.7 \\
\hline \multirow{2}{*}{$\begin{array}{c}3 \text { No } \\
\text { CORE-L } \\
\text { OC } \\
(-16.5 \mathrm{~m} \\
\text { CD) }\end{array}$} & T8 & $\begin{array}{c}200+ \\
20 \% \\
\end{array}$ & 1.2 & 14 & 7.7 \\
\hline & T9 & $\begin{array}{c}200+ \\
20 \%\end{array}$ & 0.0 & 14 & 7.7 \\
\hline
\end{tabular}

Gradiation of seaward slope quarry run is $5-500 \mathrm{~mm}$ for all tests

\section{b) Image and Video Technique}

High resolution digital cameras were set up to cover up entire test durations for each and every test. At least two pre and post cross sectional views were obtained from the top by a fixed camera. This was to calculate the displaced number of units during the assessment of toe stability. And the whole tests were recorded by digital video too. Video camera angles were approximately set to 45 degrees in plan relative to the angle of incident waves and vertically angled to observe wave breaking on the front slope and movement of armour elements. All images and videos contain date and time displays, and test condition for reference. The images and videos were used to monitor displacement of armour units and wave breaking patterns.

\section{c) Testing Procedure}

It was needed to carry out the model test with $6 \mathrm{hr}$ storm in actual condition with respective extreme wave conditions. $6 \mathrm{hr}$ period equivalent to 52 minutes in the model study (scale of 1:48) and time period of 55 minutes were assigned for the model testing.

Two sets of wave gauges were arranged to measure the wave heights. One set was placed about 1.5 times of the wave length distance away from the paddle. The other set was placed closer to the structure. Wave gauges were arranged according to the recommended procedure in DHI Wave Synthesizer user's manual to analyse separation of incident and reflected waves.

\section{d) Toe Stability}

The stability of two or three rows of CORE-LOC in the toe was monitored using the state of art image capturing techniques. The displacements of the units were quantified using overlay photos taken from fixed camera positions before and after each test. With the usage of Photoshop software, successive photos were overlaid at a fixed scale and compared to identify the displacement. The categories are used in recording displacements. $\mathrm{D}_{50}$ was considered for $\mathrm{Dn}$.

1. Displaced by between $0.1 \mathrm{Dn}$ and $0.5 \mathrm{Dn}$

2. Displaced by between $0.5 \mathrm{Dn}$ and $1.0 \mathrm{Dn}$

3. Displaced by more than 1.0Dn

The displacements of rock units in the $1.8-3.4 \mathrm{~T}$ rock layers were also monitored and calculated based on the above displacement ranges.

Following considerations were made in counting movements of CORE-LOC units.

1. Since only the displacements of CORE-LOC units are taken into account, shaking and overturning were not considered during all the test conditions.

2. Displacements occurred very close to the flume glass wall were ignored because sufficient interlocking of CORE-LOC units could not be expected due to the discontinuity of the section.

\section{RESULTS AND DISCUSSION}

Presentation of model results is based on the photographs taken by the still camera (Fig. 4) and extracted snap shots from the videos during the test.

The prime objective of these tests was to assess whether two or three rows of CORE-LOC are adequate to replace 8-12 T rock boulders in the toe.
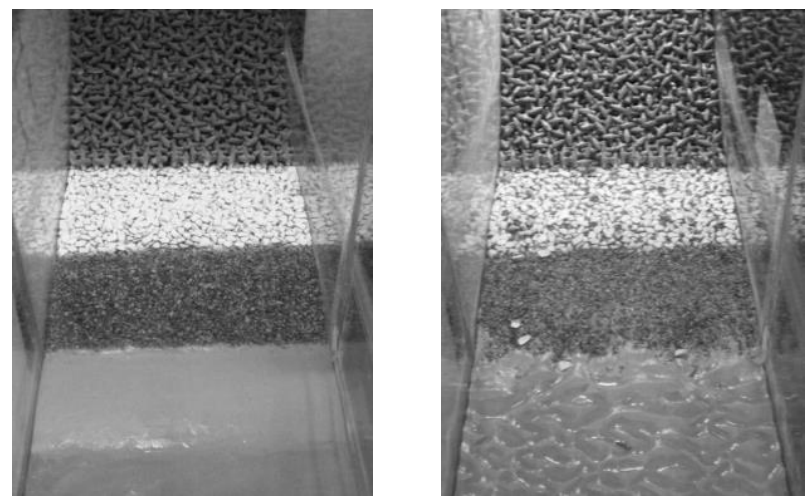

Fig. 4 Photographs Taken Before and After Testing

None of the CORE-LOCs were displaced in any test. Only a rotation of CORE-LOC in toe layer was 
observed in T5, T7, T8 and T9.

Based on the observed results during the tests, it is very much clear that the replacement of $8-12 \mathrm{~T}$ rock boulders in the Toe layer can be done with two rows of 20T CORE-LOC successfully. Although, none of the CORE-LOCs were displaced in tests, considerations must be made on application of additional CORE-LOC rows to minimize the impact which may cause due to following reasons,

1. In the alternative sections proposed for the testing, more area of rock under the original toe is exposed to the wave action.

2. With two rows of CORE-LOC, the line of transition of 1.8-3.4T rock and 1.3-2.9T rocks is exposed to the wave action directly.

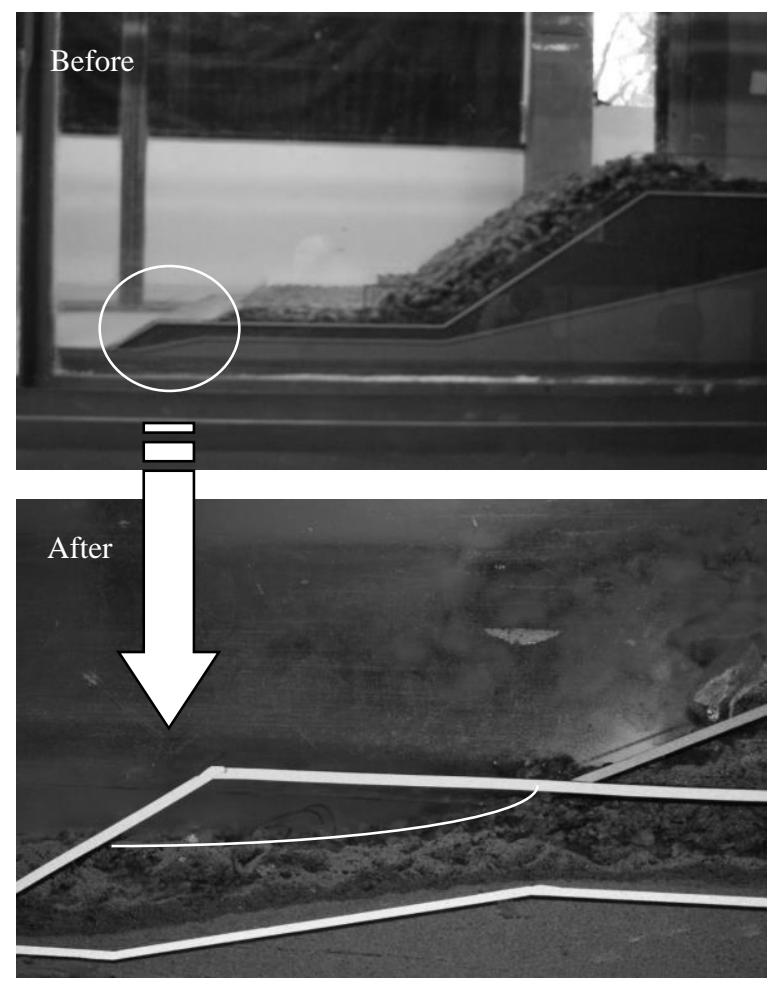

Fig. 5 Erosion of Exposed Quarry Run

In first two tests (T1 and T2), the seaward slope of 3:2 the quarry run was not stable (Fig. 5). It was subjected to erosion. As a result, new slope of 3:1 was introduced for all other tests (T3-T9). In tests $\mathrm{T} 1$ - T4, displacement of higher number of model units in 1.8-3.4T rocks was observed (Table 4). The main reason for that was the gradation of the 1.8 $-3.4 \mathrm{~T}$ model rock units had exceeded the upper limit of the gradation curve. Related to the gradation, the percentage of rocks less than the Lower Control Limit (LCL) had been exceeded the allowable limit of $10 \%$. Therefore modifications were done for the gradation and applied for tests $\mathrm{T} 5 \mathrm{-T}$.

Test T7 was carried out with the intention of assessing the stability around the transition line, where $1.3-2.9 \mathrm{~T}$ rocks are already placed up to the as-built line. During the model studies, the transition line was not exposed directly to the wave forces and was stable. In T7, four CORE - LOC rows were used with one under strength CORE-LOC row at the extreme outer seaward side. Tests from T8 to T9 were conducted for the shallow water section for water levels of $1.2 \mathrm{~m}$ and $0.0 \mathrm{~m}$. Displacement of the CORE-LOC in the toe or toe protection rows were not observed in any test performed. Only a slight rotation of one CORE-LOC in the most seaward row of toe protection row was observed. No significant movements of CORE-LOC units in the Toe or Arm of the breakwater were observed. Testing proved that seaward slope of $3: 2$ for quarry run is unstable for wave actions with higher return periods.

Table 4 Observed Displacements

\begin{tabular}{|c|c|c|c|c|c|c|c|}
\hline \multirow{2}{*}{$\begin{array}{l}\text { Test } \\
\text { Name }\end{array}$} & \multicolumn{3}{|c|}{$\begin{array}{l}\text { No. of Units } \\
\text { Displaced } \\
\text { ( In Toe Apron) }\end{array}$} & \multicolumn{3}{|c|}{$\begin{array}{l}\text { Percentage }(\%) \text { of } \\
\text { Units Displaced } \\
\text { ( In Toe Apron) }\end{array}$} & \multirow{2}{*}{$\begin{array}{l}\text { Total } \\
\text { Number } \\
\text { of units }\end{array}$} \\
\hline & $\begin{array}{r}(0.1 \\
-0.5 \\
) \mathrm{Dn} \\
\end{array}$ & $\begin{array}{c}(0.5 \\
-1) \\
\text { Dn } \\
\end{array}$ & $\begin{array}{l}>1 \\
\text { Dn }\end{array}$ & $\begin{array}{c}(0.1 \\
-0.5) \\
\text { Dn } \\
\end{array}$ & $\begin{array}{c}(0.5-1) \\
\mathrm{Dn}\end{array}$ & $\begin{array}{l}>1 \\
\text { Dn }\end{array}$ & \\
\hline $\mathrm{T} 1$ & 7 & 10 & 23 & 1.4 & 2.0 & 4.7 & \multirow{2}{*}{490} \\
\hline $\mathrm{T} 2$ & 4 & 6 & 45 & 0.8 & 1.2 & 9.2 & \\
\hline $\mathrm{T} 3$ & 1 & 7 & 24 & 0.2 & 1.5 & 5.1 & 470 \\
\hline $\mathrm{T} 4$ & 1 & 24 & 74 & 0.2 & 4.9 & 15.1 & \multirow{3}{*}{490} \\
\hline T5 & 6 & 1 & 5 & 1.2 & 0.2 & 1.0 & \\
\hline T6 & 1 & 3 & 12 & 0.2 & 0.6 & 2.5 & \\
\hline $\mathrm{T} 7$ & 3 & 2 & 9 & 0.7 & 0.4 & 2.0 & 455 \\
\hline $\mathrm{T} 8$ & 6 & 0 & 0 & 1.03 & 0 & 0 & 580 \\
\hline T9 & 15 & 0 & 0 & 2.58 & 0 & 0 & 580 \\
\hline
\end{tabular}

\section{CONCLUSION}

Based on the results observed during the 2D model tests, following conclusions can be made.

1. Two rows of 20T CORE-LOC are adequate for the replacement of $8-12 \mathrm{~T}$ rock boulders in the toe protection layer.

2. One or two additional CORE-LOC rows should be applied considering the transition of $1.3-2.9 \mathrm{~T}$ rock boulders and 1.8- $3.4 \mathrm{~T}$ rock boulders and the exposure of toe apron to the wave loading.

\section{REFERENCES}

1. Lanka Hydraulic Institute Ltd.: Colombo Port Efficiency and Expansion Project: Three dimensional Physical Model Testing., Colombo, Sri Lanka, 2004,

2. CIRIA., CUR., CETMEF. : The Rock Manual: The use of rock in hydraulic engineering, 2nd ed., C683, CIRIA, London, 2007.

3. Danish Hydraulic Institute. : DHI AWACS2 - Active Wave Absorption Control System: User Manual, Vol:1, Denmark, April 2002. 